\title{
EMBOLIA PULMONAR TROFOBLÁSTICA EM CHINCHILAS (Chinchilla laniger)
}

\author{
TROPHOBLASTIC PULMONARY EMBOLISM IN \\ CHINCHILLAS (Chinchilla laniger)
}

\section{Marcia Regina da Silva Ilha ${ }^{1}$ Pedro Soares Bezerra Júnior ${ }^{2}$ Adrien Wilhelm Dilger Sanches ${ }^{2}$ Claudio Severo Lombardo de Barros ${ }^{3}$}

\section{- NOTA -}

RESUMO

Descreve-se embolia pulmonar trofoblástica em três chinchilas e infiltracão trofoblástica no miométrio de uma delas. A idade das chinchilas variou de 14 meses a 6 anos. Uma estava no final da gestação e as outras duas no puerpério. Embolia pulmonar por células trofoblásticas é descrita em mulheres e chinchilas gestantes. Em ambas as espécies, é considerada um achado histopatológico incidental, porém em mulheres, ocasionalmente, pode levar à morte. Embolia pulmonar trofoblástica em chinchilas pode servir como um modelo animal da doença humana para o estudo da patogênese da condição em mulheres. Nesses três casos, a embolia pulmonar por células trofoblásticas foi considerada um achado histopatológico incidental.

Palavras-chave: embolia trofoblástica, pulmão, útero, patologia, chinchila.

\section{SUMMARY}

Trophoblastic pulmonary embolism is described in three chinchillas. In one of these cases there was also trophoblastic infiltration to the myometrium. The ages of the chinchillas varied from 14 months to six years. One of them was in the late gestation and the other two in the puerperium. Trophoblastic pulmonary embolism is reported in pregnant women and chinchillas. In both species it is considered an incidental finding; however, occasionally, can be the cause of death in women. Trophoblastic pulmonary embolism in chinchillas could serve as an animal model of human diseases to study the pathogenesis as it applies for the condition in women. In these three cases the embolism was considered an incidental finding.

Key words: trophoblastic embolism, lung, uterus, pathology, chinchilla.

O aumento crescente de criações de chinchilas (Chinchilla laniger) em nosso meio torna indispensável o conhecimento de algumas peculiaridades dessa espécie que possam interferir com o diagnóstico post-mortem. Descrevem-se três casos de embolia pulmonar trofoblástica em chinchilas e infiltração trofoblástica no miométrio em um deles.

As necropsias foram realizadas na seção de Patologia Veterinária da Universidade Federal de Santa Maria. Não foram encontradas alterações macroscópicas significativas. Fragmentos das diversas estruturas foram colhidos e processados para exame histológico.

A idade das chinchilas variou de 14 meses a seis anos. Uma estava no final da gestação e as outras no puerpério. Os sinais clínicos apresentados eram relacionados com a doença primária que, em dois casos, era broncopneumonia fibrinopurulenta bacteriana e, no outro, hepatite necrosante multifocal de etiologia indeterminada.

\footnotetext{
${ }^{1}$ Estudante do Curso de Medicina Veterinária da Universidade Federal de Santa Maria (UFSM), bolsita de Iniciação Científica do CNPq. ${ }^{2}$ Médico Veterinário, aluno do Programa de Pós-graduação em Medicina Veterinária da UFSM, área de concentração em Patologia Veterinária.

${ }^{3}$ Médico Veterinário, PhD. Professor Titular do Departamento de Patologia da UFSM. 97105-900 Santa Maria, RS. Bolsista do CNPq. E-mail: cslb@sm.conex.com.br. Autor para correspondência.
} 
A embolia trofoblástica foi histologicamente caracterizada pelo preenchimento de algumas porções do lúmen dos capilares alveolares por células poliédricas grandes com citoplasma fracamente eosinofílico, núcleos grandes e vesiculares e nucléolos evidentes, isoladas ou em grupos (Figura 1). No miométrio, células semelhantes formavam agregados entre as fibras da camada circular e no estrato vascular.

Embolia pulmonar por células trofoblásticas é descrita em mulheres (TROTTER \& TIECHE, 1956; HOFFMAN \& SIMONS, 1969) e chinchilas gestantes (BILLINGTON \& WEIR, 1967; TVEDTEN \& LANGHAM, 1974). Essa condição é favorecida pela placentação do tipo hemocorial, onde as células trofoblásticas estão diretamente em contato com o sangue materno (WAGNER, 1967). Células trofoblásticas desprendem-se do sincício no espaço interviloso e passam diretamente para o sistema venoso materno (BILLINGTON \& WEIR, 1967). Em ambas as espécies, é considerada um achado histopatológico incidental (BILLINGTON \& WEIR, 1967; WAGNER, 1967; TVEDTEN \& LANGHAM, 1974; SMITH et al., 1981), porém em mulheres pode levar à morte (TROTTER \& TIECHE, 1956; HOFFMAN \& SIMONS, 1969; IKARSHI et al., 1988).

Em seres humanos casos fatais estão relacionados com doenças trofoblásticas benignas ou toxemia da prenhez (TROTTER \& TIECHE, 1956, HOFLEHNER \& GOLOB, 1981, HOFFMAN \& SIMONS, 1969, SMITH et al., 1981), como uma das possíveis causas da síndrome da perturbação respi-

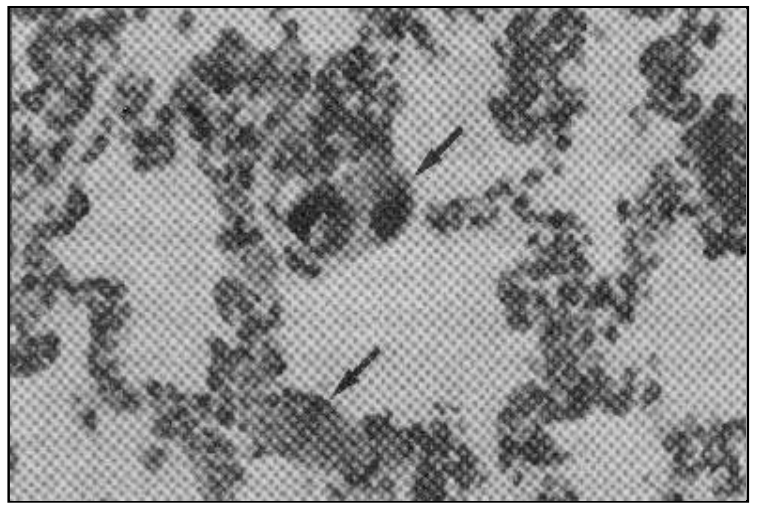

Figura 1 - Embolia pulmonar trofoblástica em chinchilas (Chinchilla laniger). Células trofoblásticas (setas) nos capilares pulmonares. H.-E. Obj. 40. ratória aguda (HOFLEHNER \& GOLOB, 1981) e como causa de morte súbita por embolia cerebral por fragmentos de células trofoblásticas (IKARSHI $\boldsymbol{e t}$ al., 1988).

Em chinchilas, a condição é somente um achado incidental não relacionado com doença clínica (BILLINGTON \& WEIR, 1967; TVEDTEN \& LANGHAM, 1974). Estudo realizado com quinze chinchilas em diversos estágios de gestação, e até dois meses após o parto, demonstrou a ocorrência de embolia trofoblástica em todos os animais. A infiltração trofoblástica no miométrio é um processo também descrito em chinchilas. A alteração permanece por longo período após o parto, podendo se estender a gestações subseqüentes. A função dessas células no miométrio é desconhecida (BILLINGTON \& WEIR, 1967).

Nestes três casos, a embolia pulmonar por células trofoblásticas foi considerada um achado histopatológico incidental. Isso deve ser levado em conta no diagnóstico de rotina nessa espécie. A embolia pulmonar por células trofoblásticas em chinchilas pode servir como um modelo animal para o estudo da doença em seres humanos.

\section{REFERÊNCIAS BIBLIOGRÁFICAS}

BILLINGTON, W.D., WEIR B.J. Deportation of trophoblast in the chinchilla. J Reprod Fert, v.13, p.593-595, 1967.

HOFLEHNER, G., GOLOB, E. Gestational trophoblastic emboli as possible cause of an acute respiratory distress syndrome. Wien Med Wochenschr, v.131, n.19, p.475-477, 1981.

IKARASHI, T., TAKEUCHI, S., OHNISHI, Y. Trophoblastic embolism in sudden maternal death. Nippon Sanka Fujinka Gakkai Zasshi, v.40, n.6, p.793-795, 1988.

ROFFMAN, B.Y., SIMONS, M. Syncytial trofhoblastic embolism associated with placenta increta and pre-eclampsia. Am J Obst \& Gynec, v.104, p.1218-1220, 1969.

SMITH, J.C., ALSULEIMAN, S. BISHOP, H., et al. Trophoblastic pulmonary embolism. South Med J, v.74, n.8, p.916-919, 1981.

TROTTER, R.F., TIECHE, H.L. Maternal death due to pulmonary embolism of trophoblastic cells. Am J Obst \& Gynec, v.71, n.5, p.1114-1118, 1956.

TVEDTEN, H.W., LANGHAM, R.F. Trophoblastic emboli in a chinchilla. J Am Vet Med Assoc, v.165, n.9, p.828-829, 1974.

WAGNER, D. Trophoblastic cells in the blood stream in normal and abnormal pregnancy. Acta Cytol, v.12, n.2, p.137-139, 1967. 